Article

\title{
Sustainability Evaluation of Power Grid Construction Projects Using Improved TOPSIS and Least Square Support Vector Machine with Modified Fly Optimization Algorithm
}

\author{
Dongxiao Niu ${ }^{1}$, Yan Li ${ }^{1}{ }^{*}$, Shuyu Dai ${ }^{1}$, Hui Kang ${ }^{1}$, Zhenyu Xue ${ }^{2}$, Xianing Jin ${ }^{2}$ and Yi Song ${ }^{2}$ \\ 1 School of Economics and Management, North China Electric Power University, Beijing 102206, China; \\ ndx@ncepu.edu.cn (D.N.); DaiShuyu@ncepu.edu.cn (S.D.); kangh@ncepu.edu.cn (H.K.) \\ 2 State Grid Economic and Technological Research Institute Co., Ltd., Beijing 102210, China; \\ xuezhenyu@chinasperi.sgcc.com.cn (Z.X.); jinxianing@chinasperi.sgcc.com.cn (X.J.); \\ songyi@chinasperi.sgcc.com.cn (Y.S.) \\ * Correspondence: ealinne13@ncepu.edu.cn; Tel.: +86-010-6177-3472
}

Received: 16 December 2017; Accepted: 15 January 2018; Published: 18 January 2018

\begin{abstract}
The electric power industry is of great significance in promoting social and economic development and improving people's living standards. Power grid construction is a necessary part of infrastructure construction, whose sustainability plays an important role in economic development, environmental protection and social progress. In order to effectively evaluate the sustainability of power grid construction projects, in this paper, we first identified 17 criteria from four dimensions including economy, technology, society and environment to establish the evaluation criteria system. After that, the grey incidence analysis was used to modify the traditional Technique for Order Preference by Similarity to an Ideal Solution (TOPSIS), which made it possible to evaluate the sustainability of electric power construction projects based on visual angle of similarity and nearness. Then, in order to simplify the procedure of experts scoring and computation, on the basis of evaluation results of the improved TOPSIS, the model using Modified Fly Optimization Algorithm (MFOA) to optimize the Least Square Support Vector Machine (LSSVM) was established. Finally, a numerical example was given to demonstrate the effectiveness of the proposed model.
\end{abstract}

Keywords: improved TOPSIS; MFOA; LS-SVM; sustainability evaluation; power grid construction projects

\section{Introduction}

Sustainability refers to the health condition of a system that can last a long time. With the concept of sustainable development getting more and more attention, many scholars have carried out a series of research projects on sustainable development of different areas. The sustainability evaluation of construction projects is to evaluate whether the objectives of projects can be achieved on schedule or bring good benefits, whether the investors are willing and able to maintain the operation goals and whether the projects have the characteristics such as continuity, repeatability and maintainability in operation.

The power grid is composed of all kinds of substations, transmission and distribution equipment in the power system. As an important carrier for connecting power supply and power users, the sustainability of power grid is crucial for power system development and scale expansion. In recent years, the power grid construction projects in China increased rapidly, making China at the forefront of the world in terms of electric power scale. According to the China Electricity Council, as of 2016 , the length of electric power transmission lines whose voltages are at least $220 \mathrm{kV}$ in China has 
reached $642,389 \mathrm{~km}$, with a growth of $5.7 \%$ over the same period of 2015; the capacity transformer equipment has risen to 3415.64 million $\mathrm{kVA}$ with an growth of $8.3 \%$. In the field of super-high voltage transmission, key technologies of High-Voltage Direct Current circuit breakers, research on large power grid planning and operation control technology have made new progress. However, some problems in power grid construction were exposed, such as the contradiction between power grid planning and local government planning on water conservancy and land planning, the low power supply reliability and the high line loss rate [1]. Therefore, it is of great necessity to introduce the concept of sustainability into power grid construction projects, identify effective evaluation criteria, and establish a comprehensive evaluation criteria system to guide the electric power construction and improve its continuity, repeatability and maintainability.

According to existing literature, the research on sustainable can be divided into two main branches: macroscopical research and microcosmic research. The research on the macro level mainly focuses on sustainable development of the world environment, countries and industrial sectors, and criteria systems were established mainly from four aspects of society, economy, environment and policy [2,3]. For the sustainability assessment of sectors, the industrial sector, transportation sector, product manufacturing and electric power system [4-7] are often set as the research objects. The research on the micro level mainly focuses on sustainable evaluation of enterprises and projects [8,9].

In particular, a great number of scholars have studied different dimensions and methods to evaluate the power grid projects [10-15]. For reliability evaluation, Adefarati et al. [10] evaluated the reliability and economic efficiency of a microgrid power system with the integration of renewable energy resources. Huang et al. [11] analyzed the mechanism of incentive-based demand response and its impact on power supply reliability, and then developed a model considering a customer's comprehensive assessment and the customer response. For stability evaluation, Song et al. [12] established a distributed framework to evaluate and improve the small-disturbance stability of a microgrid with inverter-based distributed generators. Luna et al. [13] contributed an evaluation framework to quantitatively assess the enhancement attained by different online energy management strategies. From these studies above, it can be concluded that they are related to only one or two dimensions such as economic efficiency, stability and reliability evaluation instead of comprehensive sustainability evaluation of power grid projects.

For comprehensive sustainability evaluation of power grid projects, economy, society and environment are commonly used to identify criteria to analyze the sustainability of specific power generation projects [16-18]. Rodríguez-Serrano et al. [19] conducted a sustainability impact assessment of the supply chain of a solar thermal electricity project in Mexico, using the "Framework for Integrated Sustainability Assessment". Inoussah et al. [20] evaluated the performance and sustainability indicators of various thermal power generation technologies in Cameroon using the exergy analysis tools. However, these studies mainly set electric power generation projects as analysis objects, and there are few studies that focus on power grid construction projects. According to characteristics of power grid construction projects, Wu et al. [21] introduced the contents of smart grid construction and analyzed the position of information technology and demand for smart grid construction. Feron et al. [22] took into account four dimensions of sustainability including institutional, economic, environmental, and socio-cultural to assess the sustainability of rural electrification programs based on off-grid photovoltaic systems in Chile. Zhao et al. [23] proposed a novel hybrid framework to evaluate the performance of a Strong Smart Grid from the perspective of electric power construction, operation and sustainable development.

According to the research mentioned above, it can be noted that the current studies about sustainability are mainly carried out from macro perspectives on world, countries and industrial sectors. For evaluation methods, classical evaluation methods such as Analytic Hierarchy Process and Fuzzy Comprehensive Evaluation Method are more commonly used.

In this paper, we regarded economy, technology, society and environment as four crucial factors affecting the sustainability of power grid construction projects to construct the evaluation criteria 
system, and proposed to combine improved classical evaluation methods with heuristic methods. Specifically, we used the improved Technique for Order Preference by Similarity to an Ideal Solution (TOPSIS) to evaluate and rank a number of power grid construction projects, and then the evaluation results of the TOPSIS were used to train the Least Square Support Vector Machine (LSSVM) optimized by the Modified Fly Optimization Algorithm (MFOA).

The remaining parts of this article are structured as follows: in Section 2, the sustainability evaluation criteria system of the power grid construction projects is built; in Section 3, the methodology of the improved TOPSIS and MFOA-LSSVM is introduced; a numerical example is given to verify the validity and feasibility of the model in Section 4; at last, in Section 5, we summarize the research results of this article.

The flow chart of this study is shown as Figure 1.

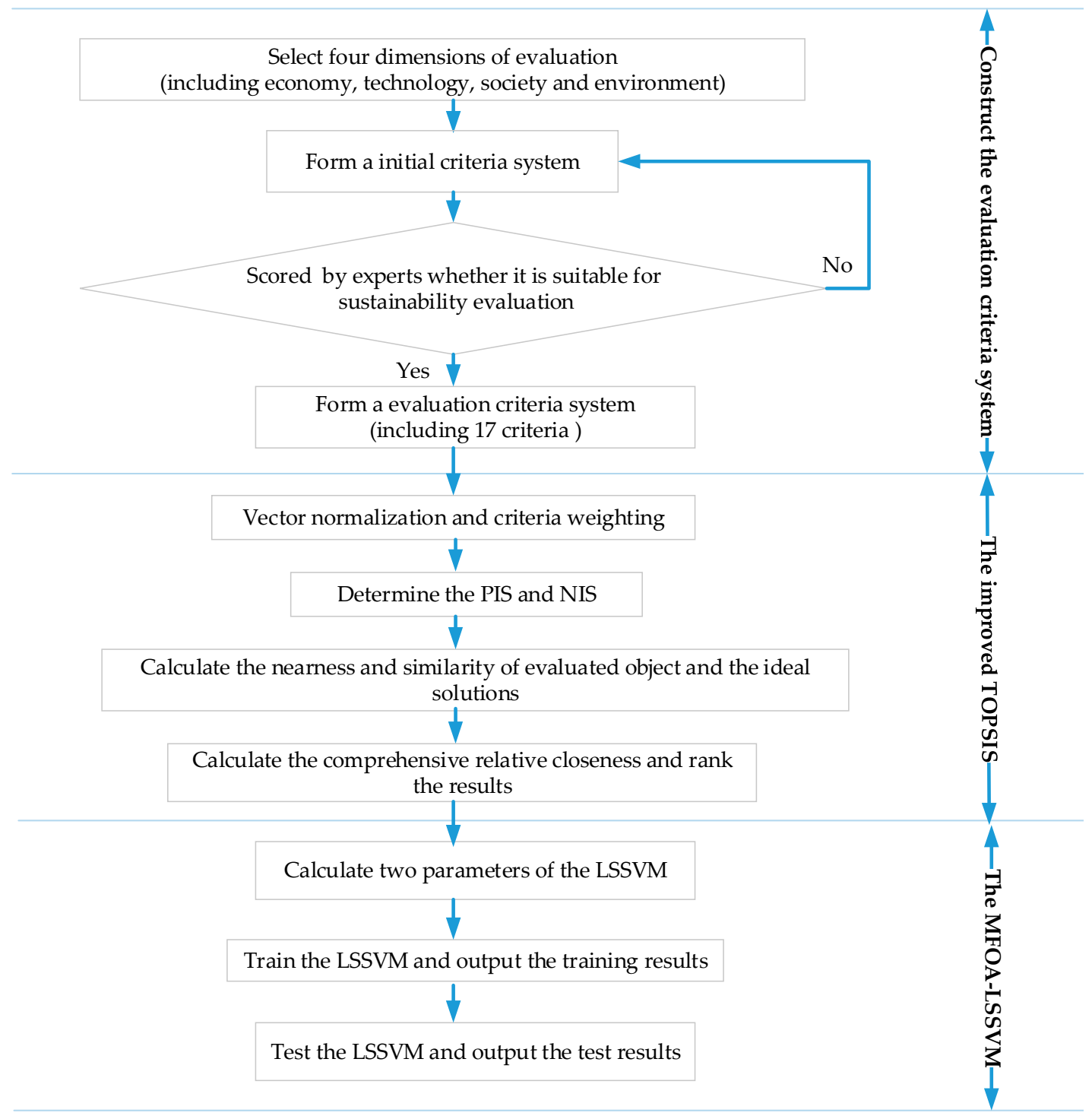

Figure 1. The flow chart of this study.

\section{Constructing an Evaluation Criteria System of Power Grid Construction Projects}

\subsection{Evaluation Criteria System Construction}

In this paper, the construction of evaluation criteria system includes the following steps: 


\subsubsection{Initially Determining Evaluation Criteria}

Through analyzing existing literature, in this paper, four main dimensions of economy, technology, society and environment are firstly taken into account to help in initially identifying 25 evaluation criteria that contain both qualitative criteria and quantitative criteria.

\subsubsection{Evaluation Criteria Selection}

The evaluation criteria system is required in which it is better to use fewer and simpler criteria under the constraints of time and cost in evaluation progress. Therefore, to use as few and simple criteria as possible, an expert scoring method was used to select the appropriate amount of criteria from the 25 criteria. In this research, five experts who mainly study on the electric power system were invited to rate the importance of each criteria ranging from 0 to 100 . The higher the score is, the more important the criterion is. The steps of expert scoring method are as follows:

First, five experts rated the 25 criteria to get the scores of each criterion; after that, we compared the scores of each criterion and fed back the analysis results to five experts and performed the second round of scoring; then, we repeated the second step until the score of each criteria from each expert would not be changed any more.

The principle to eliminate criteria from the evaluation criteria system is that if there is a criterion $j(j=1,2, \ldots, 25)$ whose score given by an expert $i(i=1,2,3,4,5)$ is lower than a given value (in this study, the value is set to be 40 ), we think the criterion $j$ is relatively unimportant for sustainability evaluation and eliminate it from the criteria system.

\subsubsection{Criteria System Construction and Criteria Weights Calculation}

According to the results of experts scoring, eight criteria were eliminated because of low scores. We then constructed the criteria system using the left 17 criteria and calculated their weights based on scores of each criterion. The steps are as follows:

Step 1: calculating the average score of each criteria

$$
\bar{k}_{j}=\frac{1}{5} \sum_{i=1}^{5} k_{i j}
$$

where $\bar{k}_{j}$ is the average score of criterion $j(j=1,2, \ldots, 17)$, and $k_{i j}$ is the score of criterion $j(j=1,2, \ldots, 17)$ given by expert $i(i=1,2,3,4,5)$.

Step 2: calculating the weights of each criterion

$$
k_{j}=\bar{k}_{j} / \sum_{j=1}^{17} \bar{k}_{j}
$$

where $k_{j}$ is the weight of criterion $j$.

The criteria system for sustainability evaluation of power grid construction projects and the weights of each criterion are shown in Figure 2. The criteria system is composed of four first-level criteria, seven second-level criteria and 17 third-level criteria. 


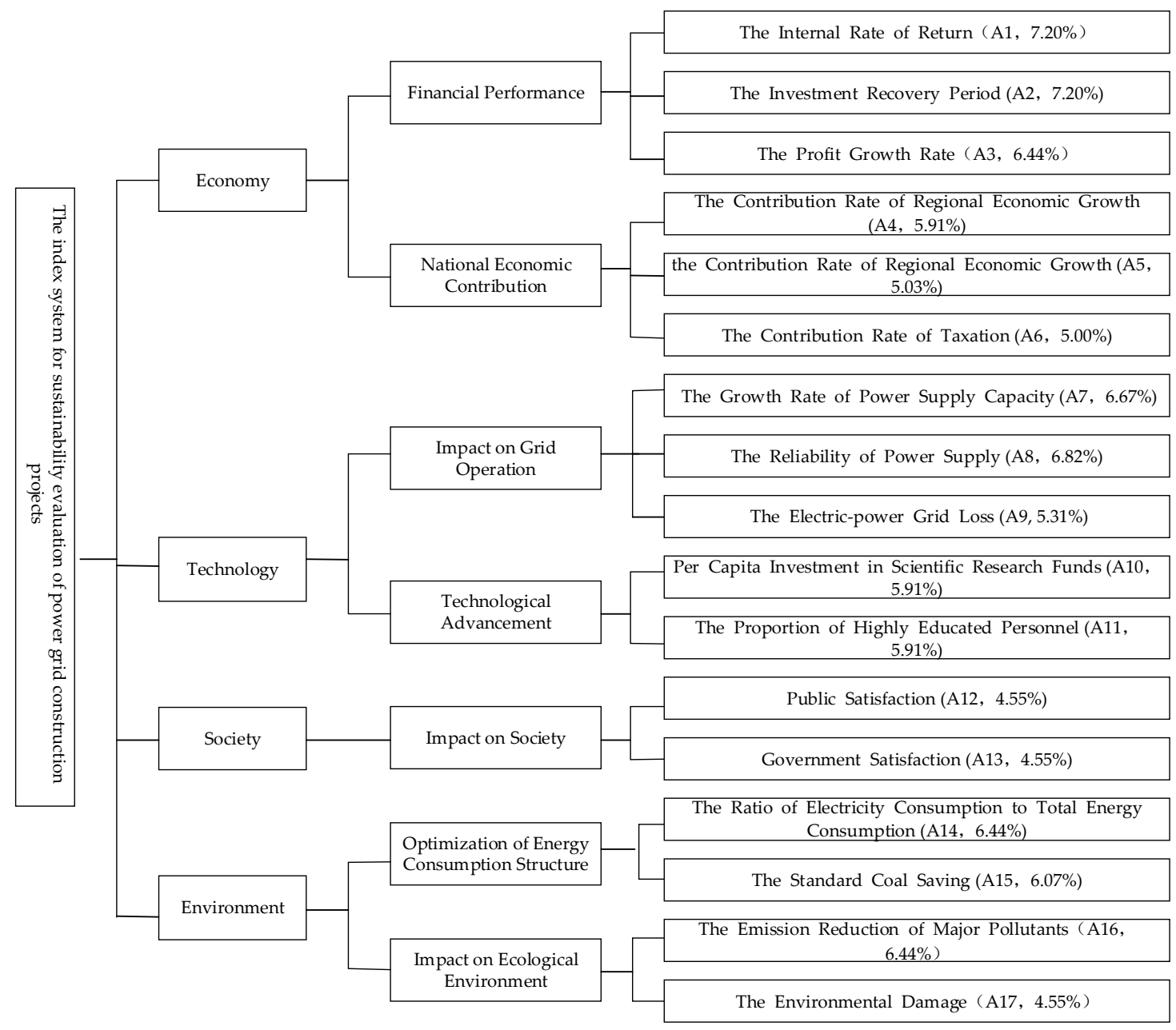

Figure 2. The criteria system for sustainability evaluation of power grid construction projects.

\subsection{Criteria Description}

\subsubsection{Economy}

From the perspective of economy, the sustainability evaluation of power grid construction projects mainly consists of two aspects, including financial performance, which is related to the investors and national economic contribution, which is related to national economic benefits. The Internal Rate of Return is the profitability of project investment, reflecting the efficiency of investment. The Investment Recovery Period refers to the period of time to repay the original investment with the net proceeds of project. The longer the investment recovery period is, the greater the risk borne by the investors. The Profit Growth Rate reflects the profitability of power grid construction project. The criterion of the Contribution Rate of Regional Economic Growth reflects the stimulating effect of the construction project on the regional economy. Because it is difficult to be measured quantitatively, this criterion is given to be scored by experts. The Number of Jobs Provided Directly reflects the role of power grid construction projects in promoting regional employment. The Contribution Rate of Taxation is expressed as the ratio of the income tax amount of the project to the enterprise income tax in the region where the project is constructed.

\subsubsection{Technology}

From the perspective of technology, sustainability evaluation of power grid construction projects mainly includes the evaluation of the impact on grid operation and the evaluation of the advanced 
technology used in the project. The Growth Rate of Power Supply Capacity is the ratio of the installed capacity of the project to the existing capacity in the evaluated area, which reflects the project's driving effect on regional power development. The Reliability of Power Supply refers to the reliability of continuous power supply to users when the grid equipment is out of service, which is a significant symbol of power supply quality. The Power grid Loss is an important criteria to evaluate the efficiency of power transmission. Per Capita Investment in Scientific Research Funds and the Proportion of Highly Educated Personnel represent the progressiveness of power grid construction projects.

\subsubsection{Society}

From the perspective of society, the sustainability evaluation mainly involves the impact and benefit of the constructed projects on local society. Therefore, to analyze the adaptability and acceptability of the local residents and government, two criteria including Public Satisfaction and Government Satisfaction are used.

\subsubsection{Environment}

From the perspective of environment, the impact of power grid construction projects on energy consumption structure and ecological environment are taken into account to evaluate the sustainability. The criterion of the Ratio of Electricity Consumption to Total Energy Consumption and the Standard Coal Saving both reflect the importance of electric energy in regional total energy consumption. In other words, they are adopted to reveal the impact of electric power construction projects in reducing primary energy use and improving energy efficiency. The Emission Reduction of Major Pollutants reflects the contribution of projects in energy saving and emission reduction. The Environmental Damage reflects the impact of grid construction projects on noise and water and soil pollution.

\section{Methodology}

\subsection{The TOPSIS Improved by the Grey Incidence Analysis}

The TOPSIS technique, also known as the Double Base Points Method, was proposed by Hwang and Yoon [24]. This technique works by setting the positive ideal solution (PIS) and the negative ideal solution (NIS) of multi-criteria decision making problems, and considering the distances to PIS and NIS of evaluated alternatives as the evaluation standard to rank all the alternatives. Therefore, the traditional TOPSIS is a technique based on distance measure. The grey incidence analysis was proposed by Professor Deng $[25,26]$, the founder of grey system theory. On the basis of work of previous scholars, Liu et al. $[27,28]$ then proposed the grey incidence analysis, which works to measure the similarity of two sequences. Therefore, the grey incidence analysis is a method based on similarity measure.

When evaluating an object, sometimes we not only need to consider the distance closeness between the evaluated object and the target object, but also the similarities between them. In other words, we need to take into consideration whether all the aspects of the evaluated object develop in balance and whether the structure is reasonable. Therefore, in this paper, we propose an improved TOPSIS based on the grey incidence analysis, considering the nearness and similarity between the evaluated objects and the target objects. The steps are as follows.

Step 1: vector normalization and criteria weighting.

Assuming that there are $m$ objects to be evaluated and $n$ evaluation criteria. The observation value of object $i$ is $d_{i j}(i=1,2, \ldots m ; j=1,2, \ldots, n)$, the observation value matrix $D=\left(d_{i j}\right)_{m \cdot n}$ can be expressed as

$$
D_{i j}=\left[\begin{array}{c}
D_{1} \\
D_{2} \\
\vdots \\
D_{m}
\end{array}\right]=\left[\begin{array}{cccc}
d_{11} & d_{12} & \cdots & d_{1 n} \\
d_{21} & d_{22} & \cdots & d_{2 n} \\
\vdots & \vdots & \ddots & \vdots \\
d_{m 1} & d_{m 2} & \cdots & d_{m n}
\end{array}\right],
$$


The vector normalization is carried out according to Equation (3):

$$
x_{i j}^{\prime}=\frac{d_{i j}}{\sqrt{\sum_{i=1}^{m} d_{i j}^{2}}}
$$

where $x_{i j}^{\prime}$ is the normalized result of $d_{i j}$.

The decision matrix $X_{i j}$ is obtained by weighting each criterion according to Equation (4):

$$
\begin{gathered}
x_{i j}=k_{j} x^{\prime}{ }_{i j} \\
X_{i j}=\left[\begin{array}{c}
X_{1} \\
X_{2} \\
\vdots \\
X_{m}
\end{array}\right]=\left[\begin{array}{cccc}
x_{11} & x_{12} & \cdots & x_{1 n} \\
x_{21} & x_{22} & \cdots & x_{2 n} \\
\vdots & \vdots & \ddots & \vdots \\
x_{m 1} & x_{m 2} & \cdots & x_{m n}
\end{array}\right]
\end{gathered}
$$

where $x_{i j}$ is the observation value of each criterion after weighting.

Step 2: determining the PIS and NIS

$$
\begin{aligned}
& X^{+}=\max _{1<i<m} x_{i}(j)=\left(x^{+}(1), x^{+}(2), \cdots, x^{+}(n)\right), \\
& X^{-}=\max _{1<i<m} x_{i}(j)=\left(x^{-}(1), x^{-}(2), \cdots, x^{-}(n)\right),
\end{aligned}
$$

where $x^{+}(j)$ and $x^{-}(j)$ are the positive ideal value and the negative ideal value of criteria $j, X^{+}$is the PIS, and $X^{-}$is the NIS.

Step 3: calculating the distance between the object $i$ and the ideal solutions

$$
D_{i}^{+}=\sqrt{\sum_{j=1}^{n}\left(x_{i}(j)-x^{+}(j)\right)^{2}},
$$

where $D_{i}^{+}$is the distance between the object $i$ and the PIS.

$$
D_{i}^{-}=\sqrt{\sum_{j=1}^{n}\left(x_{i}(j)-x^{-}(j)\right)^{2}},
$$

where $D_{i}^{+}$is the distance between the object $i$ and the NIS.

Step 4: calculating the similarity coefficient between the object $i$ and the ideal solutions

$$
\begin{aligned}
& R_{i}^{+}=\frac{X_{i} \cdot X^{+}}{\left|X_{i}\right|\left|X^{+}\right|}, \\
& R_{i}^{-}=\frac{X_{i} \cdot X^{-}}{\left|X_{i}\right|\left|X^{-}\right|},
\end{aligned}
$$

where $X_{i}=\left[x_{i 1}, x_{i 2}, \ldots, x_{i n}\right](i=1,2, \ldots, m), X^{+}=\max _{1<i<m} x_{i}(j)=\left(x^{+}(1), x^{+}(2), \cdots, x^{+}(n)\right)$, and $X^{-}=\max _{1<i<m} x_{i}(j)=\left(x^{-}(1), x^{-}(2), \cdots, x^{-}(n)\right), R_{i}^{+}$is the similarity coefficient between the object $i$ and the PIS, $R_{i}^{-}$is the similarity coefficient between the object $i$ and the NIS.

Step 5: defining the comprehensive relative closeness

$$
C_{i}=\gamma C_{D_{i}}+(1-\gamma) C_{R_{i}}=\gamma \frac{D_{i}^{-}}{D_{i}^{+}+D_{i}^{-}}+(1-\gamma) \frac{R_{i}^{+}}{R_{i}^{+}+R_{i}^{-}},
$$


where $C_{D_{i}}$ is the relative closeness that reveals the nearness between the object $i$ and the ideal solutions (target objects), $C_{R_{i}}$ is the relative closeness that reveals the similarity degree between the object $i$ and the ideal solutions (target objects), $\gamma$ is the adjustment coefficient that reveals the preference of decision makers on the similarity and nearness between the evaluated objects and target objects. If $\gamma=0$, the comprehensive relative closeness is equal to the similarity closeness, reflecting that the decision makers emphasize the similarity between the evaluated object and the target objects; If $\gamma=1$, the comprehensive relative closeness is equal to the nearness closeness, reflecting that the decision makers give priority to the distance nearness between the evaluated object and the target objects.

Step 6: ranking the preference order according to the comprehensive relative closeness.

A set of objects can be preference ranked according to the comprehensive relative closeness. The higher the comprehensive relative closeness is, the better the evaluated object is.

\subsection{The LSSVM Optimized by the MFOA}

\subsubsection{The LSSVM}

The SVM was proposed by Vapnik [29] according to the principle of structural risk minimization in statistical learning theory. It can effectively deal with problems such as few samples, nonlinear problems and high-dimensional data. The LSSVM proposed by Suykens [30-32] is an upgraded version of SVM, working by transforming the convex quadratic programming problem in the classical SVM into linear equations, so as to accelerate the training speed and improve the convergence precision. It is a class of kernel-based learning methods [33]. Now, the LSSVM has been widely used in forecasting [34-36], data fitting [37,38], comprehensive evaluation [39,40] and pattern recognition [41-43]. The steps are as follows.

Step 1: assuming that there is a training set $\left\{\left(x_{i}, y_{i}\right) \mid i=1,2, \cdots, n\right\}$ with $n$ data points, where $x_{i} \in R^{d}$ is input data and $y_{i} \in R$ is output data.

The optimization problem can be formulated as

$$
\left\{\begin{array}{l}
\min \left(\frac{1}{2}\|\omega\|^{2}+\frac{1}{2} c \sum_{i=1}^{n} \xi^{2}{ }_{i}\right) \\
\text { s.t. }: y_{i}=\omega^{T} \varphi\left(x_{i}\right)+b+\xi_{i}
\end{array},\right.
$$

where $w$ is an adjustable weight vector, $c$ is the regulation constant, $\xi_{i}$ is the relaxation factor and $b$ is bias.

Step 2: the Lagrange function can be formulated as

$$
L(\omega, b, \xi, \alpha, \gamma)=\frac{1}{2}\|\omega\|^{2}+\frac{1}{2} c \sum_{i=1}^{n} \xi_{i}^{2}-\sum_{i=1}^{n} \alpha_{i}\left[\omega^{T} \cdot \varphi\left(x_{i}\right)+b+\xi_{i}-y_{i}\right],
$$

where $\alpha_{i}(i=1,2, \cdots, n)$ is the Lagrange multipliers.

Step 3: according to the Karush-Kuhn-Tucker, Equation (14) can be obtained from Equation (13) that

$$
\left\{\begin{array}{c}
\frac{\partial L}{\partial \omega}=0 \rightarrow \omega=\sum_{i=1}^{n} \alpha_{i} \varphi\left(x_{i}\right) \\
\frac{\partial L}{\partial b}=0 \rightarrow \sum_{i=1}^{n} \alpha_{i}=0 \\
\frac{\partial L}{\partial \tilde{\xi}^{T}}=0 \rightarrow \alpha_{i}=c \xi_{i} \\
\frac{\partial L}{\partial \alpha}=0 \rightarrow \omega^{T} \varphi\left(x_{i}\right)+b+\xi_{i}-y_{i}=0,
\end{array}\right.
$$


Step 4: from Equation (14), it can be obtained that

$$
\left[\begin{array}{cccc}
0 & 1 & \cdots & 1 \\
1 & K\left(x_{1}, x_{1}\right)+\frac{1}{c} & \cdots & K\left(x_{1}, x_{n}\right) \\
\cdots & \cdots & \cdots & \cdots \\
n & K\left(x_{n}, x_{1}\right) & \cdots & K\left(x_{n}, y_{n}\right)+\frac{1}{c}
\end{array}\right]\left[\begin{array}{c}
b \\
a_{1} \\
\cdots \\
a_{n}
\end{array}\right]=\left[\begin{array}{c}
0 \\
y_{1} \\
\cdots \\
y_{n}
\end{array}\right]
$$

where $K\left(x_{i}, x_{j}\right)=\exp \left(\frac{-\left\|x-x_{i}\right\|^{2}}{2 \sigma^{2}}\right)$, which is called the radial basis function (RBF) and $\sigma$ is the width of the RBF.

Step 5: after solving $\alpha_{i}$ and $b$ with the least square method, the final LSSVM can be written as

$$
y=\sum_{i=1}^{n} \alpha_{i} K\left(x, x_{i}\right)+b
$$

\subsubsection{The MFOA}

The FOA, which derives from the behavior of fruit flies foraging, is a swarm intelligence algorithm proposed by Pan [44]. The fruit fliers can forage through the sense of smell and fly in that direction, they can also use their vision to find the position of companions and food, and then fly to them. The smell concentration of the food is related to the relative distance of the flies from the food, and the farther the distance is, the less the food smell concentration is.

Fruit flies explore the food several times, moving from a place where there is less scent to a place where there is obvious scent until they forage successfully. The steps of MFOA are as follows.

Step 1: initializing the parameters.

The number of fruit flies is set as Size, and the initialized location of fruit fly is $X_{a x i s}$ and $Y_{a x i s}$.

Step 2: for each fruit fly, random values within a certain range are taken as the direction and distance of the fruit fly, and the next location is obtained as Equations (17) and (18):

$$
\begin{aligned}
& X_{i}=X_{\text {axis }}+\operatorname{Rand}(\cdot), \\
& Y_{i}=Y_{\text {axis }}+\operatorname{Rand}(\cdot),
\end{aligned}
$$

where $X_{i}$ and $Y_{i}$ are the next location of the fruit fly $i$, and $\operatorname{Rand}(\cdot)$ is the random number related to the flying distance.

Step 3: the distance of the current foraging location to the origin $D_{i}$ and the smell concentration judgment value $S_{i}$ are to be calculated:

$$
D_{i}=\sqrt{X_{i}^{2}+Y_{i}^{2}},
$$

In classical FOA without improvement, the smell concentration judgment value equals to the inverse of distance. However, because the distance is a random value within a large range, the smell concentration judgment value may be much smaller, which leads to premature convergence and local minimum in the next calculation procedure. In this paper, the relaxation factor is introduced to optimize the smell concentration judgment value as Equation (20):

$$
S_{i}=1 / D_{i}+\alpha \cdot D_{i},
$$

where $\alpha$ is a random value obeying uniform distribution. $\alpha \cdot D_{i}$ is used to expand the distribution of smell concentration judgment value and avoid the algorithm falling into local minima. 
Step 4: according to the smell concentration judgment value $S_{i}$ and smell concentration judgment function, the smell concentration Smell $(i)$ of the individual $i$ is to be calculated:

$$
\operatorname{Smell}(i)=\operatorname{Function}\left(S_{i}\right)
$$

Step 5: the max of smell concentration and the number of the individual with best smell concentration can be obtained:

$$
[\text { BestSmell BestIndex }]=\max (\operatorname{Smell}(i))
$$

Step 6: setting the location of the individual with best smell concentration as the flight destination, the fruit fly swarm will fly towards that location:

$$
\begin{aligned}
& \text { SmellBest }=\text { BestSmell, } \\
& X_{\text {axis }}=X(\text { BestIndex }) \\
& Y_{\text {axis }}=Y(\text { BestIndex })
\end{aligned}
$$

where SmellBest is the best smell concentration.

The procedures will be executed repeatedly from step 1 to 6 until the best location has been found.

\subsubsection{The MFOA-LSSVM}

Less parameters, easy adjustment, easy computation and high accuracy make the MFOA suitable to be used to solve practical problems. The LSSVM is suitable for problems with small sample data. The evaluation on power grid projects has the following characteristics: (1) due to the long construction period and difficulty in construction of power grid construction projects, it is difficult to obtain a large number of evaluation samples in a short period of time; (2) because many criteria are qualitative, they need to be scored by an expert scoring method to be converted into quantitative criteria, leading to cumbersome expert scoring processes. Therefore, it is crucial and necessary to solve the problem of small samples and complex evaluation procedure. This is why we apply the MFOA-LSSVM to sustainability evaluation of power grid construction projects.

For LSSVM, the regulation constant $c$ and the width of the RBF $\sigma$ can be changed flexibly, which will have a significant impact on the results. Therefore, in this paper, we optimize these two parameters with the MFOA:

$$
\begin{aligned}
& c_{i}^{(j)}=k_{1} \times S_{i}^{(j)}(1,1) \\
& \sigma_{i}^{(j)}=k_{2} \times S_{i}^{(j)}(1,2)
\end{aligned},
$$

where $k_{1}$ and $k_{2}$ are two constants.

The smell concentration is defined as

$$
\operatorname{Smell}_{i}^{(j)}=R^{2}-R M S E,
$$

where $R^{2}$ is the correlation coefficient of $\sigma_{i}^{(j)}$ and $c_{i}{ }^{(j)}$, and RMSE is the standard error of the results.

\section{Case Study}

In this paper, 30 power grid construction projects in a region in north China are set as evaluated objects to be analyzed. This sector is composed of two parts: in the first part, we rank the 30 projects with improved TOPSIS according to the comprehensive relative closeness; in another part, based on the evaluation results of the first part, 25 evaluated objects are used to train the MFOA-LSSVM, and five objects are used to test the fitness goodness. 


\subsection{Case Study for Improved TOPSIS}

What should be noted is that three criteria, including Public Satisfaction, Government Satisfaction and the Environment Damage are qualitative, which need to be converted into quantitative criteria by experts scoring. Therefore, according to the performance of these projects, three experts who work in the state grid are invited to give scores ranging from 0 to 100 . Then, we set the average value of each criterion as the final score in this case study.

1. Vector normalization and criteria weighting

The data set is normalized according to Equation (3). Then, we weight each criterion according to Equation (4), and the results are listed in Appendix A Tables A1 and A2.

2. Determining the PIS and NIS

The PIS and NIS are obtained by Equations (5) and (6):

$$
\begin{aligned}
& X^{+}=\left(\begin{array}{c}
0.0158,0.0162,0.0156,0.0137,0.0127,0.0141,0.0155,0.0125 \\
0.0135,0.0133,0.0120,0.0096,0.0096,0.0143,0.0136,0.0146,0.0105
\end{array}\right), \\
& X^{-}=\left(\begin{array}{c}
0.0107,0.0086,0.0083,0.0061,0.0047,0.0036,0.0082,0.0124 \\
0.0048,0.0068,0.0094,0.0068,0.0069,0.0090,0.0084,0.0092,0.0055
\end{array}\right) .
\end{aligned}
$$

3. Calculating the distance of each object to the ideal solutions:

$$
\begin{gathered}
D_{i}^{+}=\left(\begin{array}{c}
0.0133,0.0137,0.0146,0.0171,0.0181,0.0149,0.0152,0.0126,0.0124,0.0137,0.0131,0.0127,0.0186,0.0164,0.0138 \\
0.0169,0.0163,0.0099,0.0158,0.0150,0.0123,0.0136,0.0174,0.0130,0.0135,0.0162,0.0175,0.0127,0.0121,0.0198
\end{array}\right) \\
D_{i}^{-}=\left(\begin{array}{c}
0.0166,0.0164,0.0156,0.0131,0.0102,0.0154,0.0146,0.0162,0.0186,0.0176,0.0173,0.0172,0.0133,0.0156,0.0159 \\
0.0129,0.0148,0.0187,0.0152,0.0139,0.0194,0.0169,0.0112,0.0150,0.0157,0.0144,0.0141,0.0162,0.0172,0.0097
\end{array}\right)
\end{gathered}
$$

4. Calculating the similarity coefficient of each object and the ideal solutions:

$$
\begin{aligned}
& R_{i}^{+}=\left(\begin{array}{c}
0.1150,0.1146,0.1145,0.1135,0.1141,0.1147,0.1142,0.1156,0.1148,0.1140,0.1147,0.1147,0.1121,0.1134,0.1152, \\
0.1134,0.1137,0.1161,0.1142,0.1145,0.1148,0.1149,0.1139,0.1153,0.1153,0.1143,0.1133,0.1154,0.1153,0.1124
\end{array}\right), \\
& R_{i}^{-}=\left(\begin{array}{c}
0.0876,0.0881,0.0879,0.0888,0.0896,0.0874,0.0886,0.0876,0.0872,0.0883,0.0880,0.0886,0.0887,0.0877,0.0875, \\
0.0894,0.0879,0.0869,0.0874,0.0890,0.0865,0.0872,0.0896,0.0890,0.0877,0.0876,0.0877,0.0880,0.0879,0.0899
\end{array}\right) .
\end{aligned}
$$

5. Calculating the comprehensive relative closeness

We set the adjustment coefficient $\gamma$ respectively equal to $0,0.3,0.5,0.7$ and 1 . When $\gamma=0$, it reflects that the decision makers only emphasize the similarity between the evaluated objects and the target objects; if $\gamma=0.3$, the decision makers give priority to the similarity; if $\gamma=0.5$, the decision makers think the similarity and nearness are equally important; if $\gamma=0.7$, the decision makers give priority to the nearness; if $\gamma=1$, it reflects that the decision makers only pay attention to the nearness between the evaluated objects and the target objects. Finally, we get the results corresponding to different adjustment coefficients and rank them as Table 1. 
Table 1. The results of improved TOPSIS.

\begin{tabular}{|c|c|c|c|c|c|c|c|c|c|c|}
\hline \multirow{2}{*}{ No. } & \multicolumn{2}{|c|}{$\gamma=0$} & \multicolumn{2}{|c|}{$\gamma=0.3$} & \multicolumn{2}{|c|}{$\gamma=0.5$} & \multicolumn{2}{|c|}{$\gamma=0.7$} & \multicolumn{2}{|c|}{$\gamma=1$} \\
\hline & $C_{i}$ & Rank & $C_{i}$ & Rank & $C_{i}$ & Rank & $C_{i}$ & Rank & $C_{i}$ & Rank \\
\hline 1 & 0.5705 & 2 & 0.5658 & 8 & 0.5627 & 9 & 0.5596 & 10 & 0.5625 & 7 \\
\hline 2 & 0.5663 & 12 & 0.5599 & 13 & 0.5556 & 12 & 0.5513 & 12 & 0.5743 & 5 \\
\hline 3 & 0.5684 & 5 & 0.5524 & 15 & 0.5418 & 16 & 0.5311 & 16 & 0.4328 & 26 \\
\hline 4 & 0.5676 & 9 & 0.5277 & 25 & 0.5011 & 25 & 0.4745 & 25 & 0.5390 & 13 \\
\hline 5 & 0.5652 & 16 & 0.5040 & 29 & 0.4633 & 29 & 0.4225 & 29 & 0.5876 & 4 \\
\hline 6 & 0.5640 & 19 & 0.5470 & 17 & 0.5357 & 17 & 0.5243 & 17 & 0.4751 & 22 \\
\hline 7 & 0.5640 & 18 & 0.5416 & 19 & 0.5267 & 19 & 0.5117 & 18 & 0.6536 & 1 \\
\hline 8 & 0.5599 & 27 & 0.5605 & 11 & 0.5609 & 10 & 0.5613 & 9 & 0.6005 & 3 \\
\hline 9 & 0.5674 & 10 & 0.5774 & 3 & 0.5840 & 3 & 0.5906 & 3 & 0.5151 & 16 \\
\hline 10 & 0.5643 & 17 & 0.5638 & 9 & 0.5634 & 8 & 0.5630 & 8 & 0.5619 & 8 \\
\hline 11 & 0.5679 & 7 & 0.5686 & 6 & 0.5691 & 6 & 0.5696 & 6 & 0.5073 & 17 \\
\hline 12 & 0.5662 & 13 & 0.5686 & 5 & 0.5703 & 5 & 0.5719 & 5 & 0.3614 & 29 \\
\hline 13 & 0.5611 & 25 & 0.5178 & 27 & 0.4889 & 27 & 0.4600 & 27 & 0.4470 & 24 \\
\hline 14 & 0.5658 & 14 & 0.5425 & 18 & 0.5270 & 18 & 0.5115 & 19 & 0.4909 & 18 \\
\hline 15 & 0.5591 & 28 & 0.5519 & 16 & 0.5472 & 15 & 0.5424 & 15 & 0.5353 & 15 \\
\hline 16 & 0.5602 & 26 & 0.5220 & 26 & 0.4965 & 26 & 0.4710 & 26 & 0.4711 & 23 \\
\hline 17 & 0.5684 & 6 & 0.5404 & 20 & 0.5217 & 22 & 0.5031 & 22 & 0.5539 & 11 \\
\hline 18 & 0.5557 & 30 & 0.5850 & 1 & 0.6046 & 1 & 0.6242 & 1 & 0.5549 & 10 \\
\hline 19 & 0.5582 & 29 & 0.5380 & 23 & 0.5245 & 20 & 0.5111 & 20 & 0.4808 & 21 \\
\hline 20 & 0.5637 & 22 & 0.5388 & 22 & 0.5223 & 21 & 0.5057 & 21 & 0.6124 & 2 \\
\hline 21 & 0.5673 & 11 & 0.5808 & 2 & 0.5899 & 2 & 0.5989 & 2 & 0.5448 & 12 \\
\hline 22 & 0.5628 & 24 & 0.5601 & 12 & 0.5584 & 11 & 0.5566 & 11 & 0.5703 & 6 \\
\hline 23 & 0.5657 & 15 & 0.5137 & 28 & 0.4790 & 28 & 0.4443 & 28 & 0.5611 & 9 \\
\hline 24 & 0.5640 & 20 & 0.5557 & 14 & 0.5502 & 14 & 0.5447 & 14 & 0.4882 & 20 \\
\hline 25 & 0.5721 & 1 & 0.5622 & 10 & 0.5556 & 13 & 0.5490 & 13 & 0.4167 & 27 \\
\hline 26 & 0.5689 & 3 & 0.5396 & 21 & 0.5200 & 23 & 0.5004 & 23 & 0.3923 & 28 \\
\hline 27 & 0.5631 & 23 & 0.5283 & 24 & 0.5051 & 24 & 0.4818 & 24 & 0.5364 & 14 \\
\hline 28 & 0.5685 & 4 & 0.5663 & 7 & 0.5648 & 7 & 0.5634 & 7 & 0.4893 & 19 \\
\hline 29 & 0.5637 & 21 & 0.5709 & 4 & 0.5756 & 4 & 0.5804 & 4 & 0.4346 & 25 \\
\hline 30 & 0.5677 & 8 & 0.4961 & 30 & 0.4483 & 30 & 0.4006 & 30 & 0.3290 & 30 \\
\hline
\end{tabular}

It can be concluded that the comprehensive relative closeness $C_{i}$ of evaluated object $i$ differs because of the changing of the adjustment coefficient $\gamma$, leading to the ranking changing among all the evaluated objects. Here, we take the object 7 and object 25 as examples to analyze the results. For object 7 , when $\gamma=1$, that is, the decision makers only emphasize the nearness between the evaluated object and the target objects, object 7 ranks in the first place among the 30 objects, reflecting that it is highly close to the PIS from the perspective of distance; however, when $\gamma=0$, in other words, when the decision makers only emphasize the similarity between the evaluated object and the target objects, object 7 ranks 18 th among the 30 objects, reflecting that it is at the middle level, that is, the balance of all the criteria of object 7 is at a general level. For object 25 , when $\gamma=0$, object 25 ranks in the first place, reflecting that all the criteria of object 25 develop in balance; however, when $\gamma=1$, object 25 ranks 27th out of 30 objects, reflecting that it is far away from the PIS from the perspective of distance.

\subsection{Case Study for MFOA-LSSVM}

The MFOA is used to optimize two parameters $c$ and $\sigma$ in this part. The Size equals 20, and the maximum generation equals 100 .

As is shown in Figure 3, in the iterative procedure, the convergence appears on the 12th generation with Root Mean Square Error (RMSE) of $0.62 \%$. The best regulation constant and width of the RBF are 45.51 and 0.01 , respectively. 


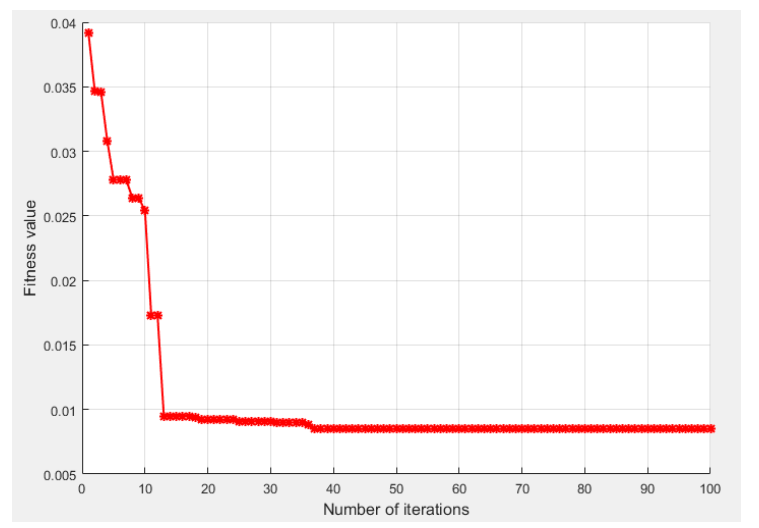

Figure 3. The iterative RMSE trend of the MFOA-LSSVM.

The data in Appendix A are set as the input of the optimized LSSVM, and the comprehensive relative closeness when $\gamma=0.5$ calculated by improved TOPSIS are set as the output. To test the rationality of the proposed model, we choose the single LSSVM without parameter optimization as a contrast to get the training results, and the results are as shown in the following Figures 4 and 5, and Tables 2 and 3.

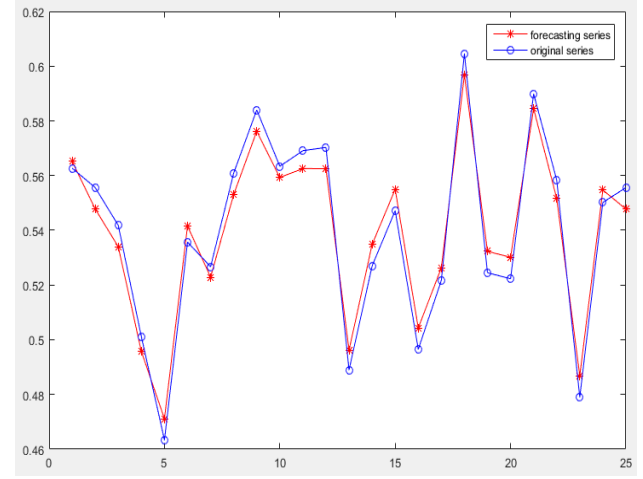

(a)

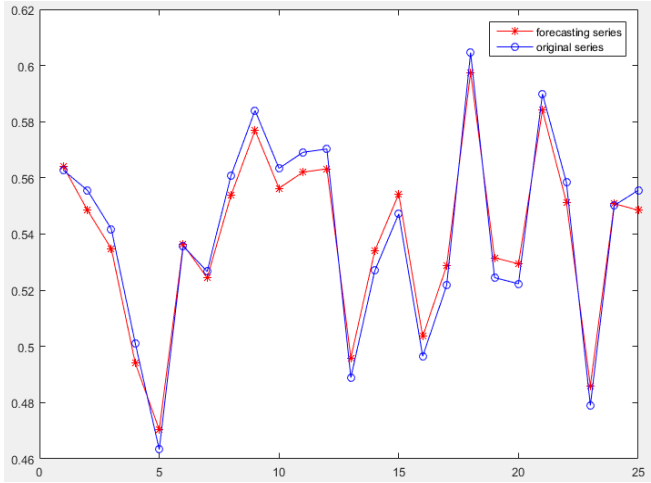

(b)

Figure 4. The training results of MFOA-LSSVM and LSSVM: (a) the training results of MFOA-LSSVM; (b) the training results of LSSVM.

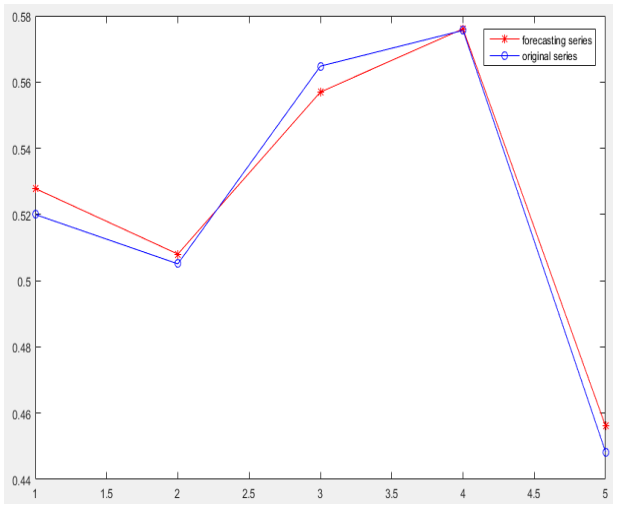

(a)

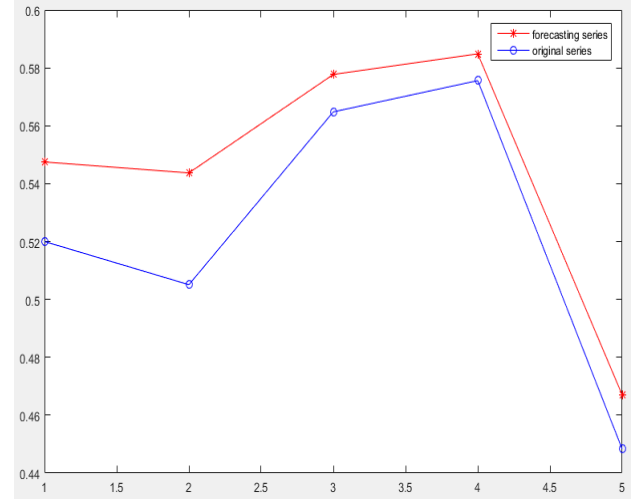

(b)

Figure 5. The test results of MFOA-LSSVM and LSSVM: (a) the test results of MFOA-LSSVM; (b) the test results of LSSVM. 
Table 2. The training results of MFOA-LSSVM and LSSVM.

\begin{tabular}{cccccc}
\hline \multirow{2}{*}{ No. } & \multirow{2}{*}{$\boldsymbol{C}_{\boldsymbol{i}}$} & \multicolumn{2}{c}{ MFOA-LSSVM } & \multicolumn{2}{c}{ LSSVM } \\
\cline { 3 - 6 } & & Training Results & Relative Error (\%) & Training Results & Relative Error (\%) \\
\hline 1 & 0.5627 & 0.5652 & 0.0044 & 0.5640 & 0.0023 \\
2 & 0.5556 & 0.5478 & 0.0141 & 0.5486 & 0.0127 \\
3 & 0.5418 & 0.5340 & 0.0145 & 0.5348 & 0.0130 \\
4 & 0.5011 & 0.4957 & 0.0108 & 0.4940 & 0.0141 \\
5 & 0.4633 & 0.4711 & 0.0169 & 0.4704 & 0.0152 \\
6 & 0.5357 & 0.5416 & 0.0110 & 0.5362 & 0.0010 \\
7 & 0.5267 & 0.5229 & 0.0073 & 0.5244 & 0.0044 \\
8 & 0.5609 & 0.5531 & 0.0139 & 0.5538 & 0.0126 \\
9 & 0.584 & 0.5762 & 0.0134 & 0.5769 & 0.0121 \\
10 & 0.5634 & 0.5593 & 0.0073 & 0.5563 & 0.0126 \\
11 & 0.5691 & 0.5626 & 0.0114 & 0.5620 & 0.0124 \\
12 & 0.5703 & 0.5625 & 0.0137 & 0.5632 & 0.0124 \\
13 & 0.4889 & 0.4962 & 0.0149 & 0.4959 & 0.0144 \\
14 & 0.527 & 0.5348 & 0.0149 & 0.5341 & 0.0134 \\
15 & 0.5472 & 0.5550 & 0.0142 & 0.5543 & 0.0130 \\
16 & 0.4965 & 0.5043 & 0.0157 & 0.5036 & 0.0143 \\
17 & 0.5217 & 0.5263 & 0.0088 & 0.5287 & 0.0134 \\
18 & 0.6046 & 0.5968 & 0.0129 & 0.5975 & 0.0117 \\
19 & 0.5245 & 0.5323 & 0.0149 & 0.5316 & 0.0135 \\
20 & 0.5223 & 0.5301 & 0.0150 & 0.5294 & 0.0136 \\
21 & 0.5899 & 0.5845 & 0.0092 & 0.5841 & 0.0099 \\
22 & 0.5584 & 0.5516 & 0.0121 & 0.5513 & 0.0126 \\
23 & 0.479 & 0.4868 & 0.0164 & 0.4860 & 0.0147 \\
24 & 0.5502 & 0.5547 & 0.0083 & 0.5508 & 0.0011 \\
25 & 0.5556 & 0.5478 & 0.0141 & 0.5485 & 0.0128 \\
\hline
\end{tabular}

Table 3. The test results of MFOA-LSSVM and LSSVM.

\begin{tabular}{cccccc}
\hline \multirow{2}{*}{ No. } & \multirow{2}{*}{$\boldsymbol{C}_{\boldsymbol{i}}$} & \multicolumn{2}{c}{ MFOA-LSSVM } & \multicolumn{2}{c}{ LSSVM } \\
\cline { 3 - 6 } & & Test Results & Relative Error (\%) & Test Results & Relative Error (\%) \\
\hline 1 & 0.5200 & 0.5278 & 0.0151 & 0.5475 & 0.0528 \\
2 & 0.5051 & 0.5080 & 0.0058 & 0.5437 & 0.0764 \\
3 & 0.5648 & 0.5570 & 0.0139 & 0.5777 & 0.0229 \\
4 & 0.5756 & 0.5761 & 0.0008 & 0.5848 & 0.0160 \\
5 & 0.4483 & 0.4561 & 0.0174 & 0.4670 & 0.0418 \\
\hline
\end{tabular}

From Figure 4 and Table 2, we can conclude that overall the relative error of the MFOA-LSSVM almost equals that of the single LSSVM.

From Figure 5 and Table 3, though the gaps of training results between the MFOA-LSSVM and the single LSSVM are not obvious, the test results of MFOA-LSSVM with a mean relative error of $1.0592 \%$ are more accurate than that of single LSSVM with a mean relative error of $4.1997 \%$, showing that the MFOA-LSSVM is suitable for sustainability evaluation of electric power gird construction projects.

When carrying out comprehensive evaluation, if there are few evaluated samples, the improved TOPSIS can be directly used. However, when the sample being evaluated increases, the improved TOPSIS requires complex calculations procedures, which will increase the evaluation difficulty and time cost. Hence, a part of the samples can be selected to carry out evaluation procedures with the improved TOPSIS to get their comprehensive relative closeness. Then, the criteria data of these samples can be used as input and the comprehensive relative closeness can be used as output to train the MFOA-LSSVM. After that, the evaluation of remaining samples can be completed with the trained MFOA-LSSVM to avoid complex computation. 
In addition to the sustainability evaluation of power grid construction projects, other comprehensive evaluation problems can also adopt this method or idea proposed in this paper. Here, we take the performance evaluation of carbon emission reduction in 30 cities in North China as an example. First, after identifying the evaluation criteria and data processing, the final ranking standard (if using the TOPSIS, the ranking standard refers to the comprehensive relative closeness) of these cities can be obtained by the improved TOPSIS or other evaluation methods such as Fuzzy Comprehensive Evaluation. By the performance ranking of carbon emission reduction in these 30 cities, suggests and policies can be given to strengthen the management of the regions with poor carbon emission reduction effect. However, when the evaluated region extends from 30 cities in North China to more than 600 cities in whole country, the traditional ranking evaluation method is not suitable to deal with a large number of calculation processes. Hence, data of 30 cities in North China can be used to train the MFOA-LSSVM model. Then, we can evaluate the performance of all the cities using the trained model, so as to reduce the calculation difficulty.

The main contribution of this method in paper is to combine classical evaluation methods with heuristic methods. The classical evaluation method, which is responsible for evaluating objects and getting the ranking standard, has a disadvantage that when there are a large number of evaluated samples, the calculation is complicated and inconvenient to operate. Heuristic methods that can be used for evaluation of a large number of samples are used to make up for the shortcoming of the traditional evaluation methods. In addition to combining the improved TOPSIS and MFOA-LSSVM, the application can be developed for other classical evaluation methods such as Fuzzy Comprehensive Evaluation Method and the Grey Fixed Weight Clustering Method and other heuristic methods such as Particle Swarm Optimization Algorithm and Artificial Neural Networks Algorithm.

\section{Conclusions}

To evaluate the sustainability of power grid construction projects, in this paper, we firstly identified 17 criteria to establish the criteria system. After that, the TOPSIS improved by grey incidence analysis was proposed to evaluate the sustainability on visual angle of similarity and nearness. Then, the MFOA-LSSVM model was applied to the sustainability evaluation of power grid construction projects. At last, a case was used to prove the rationality and feasibility of the improved TOPSIS and MFOA-LSSVM.

The highlights of this article are as follows:

1. In this paper, we construct the criteria system of the sustainability evaluation of power grid construction projects from four dimensions of economy, technology, environment and society.

2. The grey incidence analysis, which reveals the similarity between the evaluated objects and ideal objects, is used to improve the traditional TOPSIS, which reveals the nearness of the evaluated objects and ideal targets, so we can make it analyze the evaluated objects from the aspects of similarity and nearness. By this method, we rank these objects according to their comprehensive relative closeness scores.

3. We optimize two key parameters of the LSSVM using the MFOA. Based on the evaluation results of improved TOPSIS, the MFOA-LSSVM model is used to evaluate the sustainability of power grid construction projects, which simplifies the process of expert scoring and computation to help in rapid and accurate evaluation of a large number of similar projects.

4. We proposed combining the classical evaluation methods with heuristic methods. This model we have developed has wide applicability on evaluation problems.

Acknowledgments: This work was supported by the Natural Science Foundation of China (Project No. 71471059), and it was one of the results of the project called "Research and Application of Equipment Statistical Analysis System and Decision-Making Model of Grid Development Based on Real-time Information" (Project No. B3441317K008). 
Author Contributions: Dongxiao Niu provided professional guidance; Yan Li wrote this paper; Shuyu Dai carried out program debugging in MATLAB (R2015b, The MathWorks, Inc., Natick, MA, USA). Other authors collected and organized the data. All authors had approved the submitted manuscript.

Conflicts of Interest: The authors declare no conflict of interest.

\section{Appendix A}

Table A1. Vector normalization and criteria weighting $\left(A_{1}-A_{8}\right)$.

\begin{tabular}{|c|c|c|c|c|c|c|c|c|}
\hline No. & $A_{1}$ & $A_{2}$ & $A_{3}$ & $A_{4}$ & $A_{5}$ & $A_{6}$ & $A_{7}$ & $A_{8}$ \\
\hline 1 & 0.0126 & 0.0130 & 0.0116 & 0.0137 & 0.0075 & 0.0090 & 0.0087 & 0.0125 \\
\hline 2 & 0.0151 & 0.0086 & 0.0156 & 0.0101 & 0.0068 & 0.0102 & 0.0148 & 0.0124 \\
\hline 3 & 0.0151 & 0.0151 & 0.0100 & 0.0079 & 0.0101 & 0.0116 & 0.0124 & 0.0125 \\
\hline 4 & 0.0128 & 0.0140 & 0.0130 & 0.0082 & 0.0121 & 0.0047 & 0.0089 & 0.0124 \\
\hline 5 & 0.0148 & 0.0130 & 0.0086 & 0.0089 & 0.0074 & 0.0076 & 0.0100 & 0.0124 \\
\hline 6 & 0.0136 & 0.0140 & 0.0099 & 0.0117 & 0.0113 & 0.0062 & 0.0105 & 0.0125 \\
\hline 7 & 0.0141 & 0.0151 & 0.0110 & 0.0128 & 0.0089 & 0.0043 & 0.0138 & 0.0125 \\
\hline 8 & 0.0114 & 0.0130 & 0.0129 & 0.0122 & 0.0102 & 0.0117 & 0.0131 & 0.0125 \\
\hline 9 & 0.0137 & 0.0162 & 0.0145 & 0.0123 & 0.0113 & 0.0056 & 0.0146 & 0.0125 \\
\hline 10 & 0.0117 & 0.0151 & 0.0085 & 0.0132 & 0.0100 & 0.0046 & 0.0141 & 0.0125 \\
\hline 11 & 0.0138 & 0.0162 & 0.0100 & 0.0114 & 0.0063 & 0.0075 & 0.0154 & 0.0124 \\
\hline 12 & 0.0152 & 0.0119 & 0.0098 & 0.0099 & 0.0122 & 0.0064 & 0.0152 & 0.0125 \\
\hline 13 & 0.0109 & 0.0086 & 0.0144 & 0.0071 & 0.0085 & 0.0049 & 0.0152 & 0.0125 \\
\hline 14 & 0.0120 & 0.0162 & 0.0089 & 0.0136 & 0.0118 & 0.0045 & 0.0114 & 0.0124 \\
\hline 15 & 0.0138 & 0.0097 & 0.0146 & 0.0135 & 0.0080 & 0.0099 & 0.0105 & 0.0125 \\
\hline 16 & 0.0116 & 0.0130 & 0.0130 & 0.0092 & 0.0090 & 0.0046 & 0.0130 & 0.0124 \\
\hline 17 & 0.0112 & 0.0119 & 0.0099 & 0.0134 & 0.0047 & 0.0082 & 0.0155 & 0.0124 \\
\hline 18 & 0.0130 & 0.0119 & 0.0126 & 0.0120 & 0.0113 & 0.0129 & 0.0120 & 0.0124 \\
\hline 19 & 0.0109 & 0.0097 & 0.0111 & 0.0102 & 0.0127 & 0.0046 & 0.0141 & 0.0124 \\
\hline 20 & 0.0158 & 0.0130 & 0.0102 & 0.0075 & 0.0063 & 0.0113 & 0.0114 & 0.0125 \\
\hline 21 & 0.0107 & 0.0162 & 0.0138 & 0.0134 & 0.0124 & 0.0141 & 0.0100 & 0.0125 \\
\hline 22 & 0.0111 & 0.0086 & 0.0089 & 0.0093 & 0.0104 & 0.0130 & 0.0128 & 0.0124 \\
\hline 23 & 0.0124 & 0.0130 & 0.0083 & 0.0086 & 0.0065 & 0.0079 & 0.0116 & 0.0125 \\
\hline 24 & 0.0154 & 0.0130 & 0.0130 & 0.0080 & 0.0068 & 0.0110 & 0.0102 & 0.0124 \\
\hline 25 & 0.0152 & 0.0130 & 0.0135 & 0.0129 & 0.0072 & 0.0123 & 0.0090 & 0.0125 \\
\hline 26 & 0.0118 & 0.0162 & 0.0128 & 0.0085 & 0.0047 & 0.0130 & 0.0097 & 0.0124 \\
\hline 27 & 0.0135 & 0.0086 & 0.0115 & 0.0119 & 0.0118 & 0.0036 & 0.0082 & 0.0125 \\
\hline 28 & 0.0130 & 0.0140 & 0.0120 & 0.0095 & 0.0060 & 0.0135 & 0.0111 & 0.0124 \\
\hline 29 & 0.0122 & 0.0151 & 0.0126 & 0.0100 & 0.0050 & 0.0116 & 0.0135 & 0.0125 \\
\hline 30 & 0.0133 & 0.0108 & 0.0110 & 0.0061 & 0.0067 & 0.0040 & 0.0082 & 0.0124 \\
\hline
\end{tabular}

Table A2. Vector normalization and criteria weighting $\left(A_{9}-A_{17}\right)$.

\begin{tabular}{cccccccccc}
\hline No. & $\boldsymbol{A}_{\mathbf{9}}$ & $\boldsymbol{A}_{\mathbf{1 0}}$ & $\boldsymbol{A}_{\mathbf{1 1}}$ & $\boldsymbol{A}_{\mathbf{1 2}}$ & $\boldsymbol{A}_{\mathbf{1 3}}$ & $\boldsymbol{A}_{\mathbf{1 4}}$ & $\boldsymbol{A}_{\mathbf{1 5}}$ & $\boldsymbol{A}_{\mathbf{1 6}}$ & $\boldsymbol{A}_{\mathbf{1 7}}$ \\
\hline 1 & 0.0127 & 0.0131 & 0.0094 & 0.0081 & 0.0083 & 0.0139 & 0.0120 & 0.0112 & 0.0064 \\
2 & 0.0089 & 0.0121 & 0.0115 & 0.0077 & 0.0071 & 0.0097 & 0.0133 & 0.0123 & 0.0075 \\
3 & 0.0058 & 0.0107 & 0.0095 & 0.0080 & 0.0095 & 0.0094 & 0.0136 & 0.0096 & 0.0091 \\
4 & 0.0072 & 0.0102 & 0.0120 & 0.0075 & 0.0085 & 0.0141 & 0.0091 & 0.0094 & 0.0075 \\
5 & 0.0053 & 0.0106 & 0.0107 & 0.0074 & 0.0088 & 0.0096 & 0.0107 & 0.0094 & 0.0086 \\
6 & 0.0127 & 0.0114 & 0.0109 & 0.0076 & 0.0069 & 0.0090 & 0.0097 & 0.0092 & 0.0099 \\
7 & 0.0095 & 0.0103 & 0.0106 & 0.0080 & 0.0090 & 0.0091 & 0.0086 & 0.0121 & 0.0084 \\
8 & 0.0085 & 0.0068 & 0.0106 & 0.0068 & 0.0088 & 0.0126 & 0.0111 & 0.0105 & 0.0105 \\
9 & 0.0130 & 0.0114 & 0.0094 & 0.0081 & 0.0073 & 0.0133 & 0.0084 & 0.0102 & 0.0080 \\
10 & 0.0104 & 0.0122 & 0.0116 & 0.0094 & 0.0090 & 0.0142 & 0.0132 & 0.0116 & 0.0102 \\
11 & 0.0135 & 0.0091 & 0.0114 & 0.0077 & 0.0084 & 0.0124 & 0.0111 & 0.0110 & 0.0104 \\
12 & 0.0121 & 0.0098 & 0.0117 & 0.0094 & 0.0092 & 0.0143 & 0.0122 & 0.0127 & 0.0065 \\
\hline
\end{tabular}


Table A2. Cont.

\begin{tabular}{cccccccccc}
\hline No. & $\boldsymbol{A}_{\mathbf{9}}$ & $\boldsymbol{A}_{\mathbf{1 0}}$ & $\boldsymbol{A}_{\mathbf{1 1}}$ & $\boldsymbol{A}_{\mathbf{1 2}}$ & $\boldsymbol{A}_{\mathbf{1 3}}$ & $\boldsymbol{A}_{\mathbf{1 4}}$ & $\boldsymbol{A}_{\mathbf{1 5}}$ & $\boldsymbol{A}_{\mathbf{1 6}}$ & $\boldsymbol{A}_{\mathbf{1 7}}$ \\
\hline 13 & 0.0050 & 0.0074 & 0.0111 & 0.0078 & 0.0084 & 0.0127 & 0.0132 & 0.0128 & 0.0097 \\
14 & 0.0094 & 0.0072 & 0.0100 & 0.0090 & 0.0073 & 0.0119 & 0.0092 & 0.0146 & 0.0072 \\
15 & 0.0109 & 0.0128 & 0.0102 & 0.0089 & 0.0074 & 0.0097 & 0.0089 & 0.0106 & 0.0082 \\
16 & 0.0048 & 0.0101 & 0.0106 & 0.0079 & 0.0076 & 0.0136 & 0.0119 & 0.0142 & 0.0058 \\
17 & 0.0107 & 0.0077 & 0.0120 & 0.0085 & 0.0087 & 0.0099 & 0.0085 & 0.0143 & 0.0072 \\
18 & 0.0130 & 0.0124 & 0.0105 & 0.0089 & 0.0088 & 0.0118 & 0.0117 & 0.0092 & 0.0088 \\
19 & 0.0127 & 0.0113 & 0.0095 & 0.0080 & 0.0094 & 0.0125 & 0.0097 & 0.0102 & 0.0073 \\
20 & 0.0090 & 0.0086 & 0.0105 & 0.0093 & 0.0088 & 0.0129 & 0.0128 & 0.0114 & 0.0055 \\
21 & 0.0073 & 0.0088 & 0.0120 & 0.0096 & 0.0079 & 0.0104 & 0.0118 & 0.0138 & 0.0070 \\
22 & 0.0096 & 0.0130 & 0.0105 & 0.0094 & 0.0091 & 0.0124 & 0.0108 & 0.0144 & 0.0094 \\
23 & 0.0058 & 0.0115 & 0.0110 & 0.0084 & 0.0096 & 0.0094 & 0.0112 & 0.0137 & 0.0066 \\
24 & 0.0094 & 0.0099 & 0.0113 & 0.0087 & 0.0071 & 0.0115 & 0.0132 & 0.0131 & 0.0093 \\
25 & 0.0086 & 0.0114 & 0.0097 & 0.0075 & 0.0073 & 0.0109 & 0.0102 & 0.0121 & 0.0062 \\
26 & 0.0073 & 0.0091 & 0.0109 & 0.0081 & 0.0070 & 0.0107 & 0.0092 & 0.0107 & 0.0091 \\
27 & 0.0108 & 0.0121 & 0.0098 & 0.0071 & 0.0076 & 0.0093 & 0.0116 & 0.0122 & 0.0090 \\
28 & 0.0087 & 0.0126 & 0.0117 & 0.0082 & 0.0077 & 0.0113 & 0.0122 & 0.0108 & 0.0097 \\
29 & 0.0105 & 0.0133 & 0.0107 & 0.0088 & 0.0081 & 0.0138 & 0.0107 & 0.0105 & 0.0093 \\
30 & 0.0071 & 0.0123 & 0.0117 & 0.0082 & 0.0092 & 0.0129 & 0.0088 & 0.0115 & 0.0073 \\
\hline
\end{tabular}

\section{References}

1. Zhou, X.; Yi, J.; Song, R.; Yang, X.; Li, Y.; Tang, H. An overview of power transmission systems in China. Energy 2010, 35, 4302-4312. [CrossRef]

2. Dzonzi-Undi, J.; Li, S. SWOT analysis of safety and environmental regulation for China and USA: Its effect and influence on sustainable development of the coal industry. Environ. Earth Sci. 2015, 74, 6395-6406. [CrossRef]

3. Xu, Z.; Cheng, G.; Chen, D.; Templet, P.H. Economic diversity, development capacity and sustainable development of China. Ecol. Econ. 2002, 40, 369-378. [CrossRef]

4. Mayyas, A.; Qattawi, A.; Omar, M.; Shan, D. Design for sustainability in automotive industry: A comprehensive review. Renew. Sustain. Eng. Rev. 2012, 16, 1845-1862. [CrossRef]

5. Shiau, T.A.; Liu, J.S. Developing an indicator system for local governments to evaluate transport sustainability strategies. Ecol. Indic. 2013, 34, 361-371. [CrossRef]

6. Shin, D.; Curtis, M.; Huisingh, D.; Zwetsloot, G.I. Development of a sustainability policy model for promoting cleaner production: A knowledge integration approach. J. Clean. Prod. 2008, 16, 1823-1837. [CrossRef]

7. Silalertruksa, T.; Gheewala, S.H. Environmental sustainability assessment of bio-ethanol production in Thailand. Energy 2009, 34, 1933-1946. [CrossRef]

8. Chen, Y.H.; Niu, D.X.; Peng, Z. The comprehensive evaluation of sustainable development effect in regional electricity enterprises. Adv. Mater. Res. 2012, 524, 482-484. [CrossRef]

9. Peruzzini, M.; Germani, M.; Marilungo, E. Product Lifecycle Management for Society; Springer: Berlin/Heidelberg, Germany, 2013; pp. 100-109.

10. Adefarati, T.; Bansal, R.C. Reliability and economic assessment of a microgrid power system with the integration of renewable energy resources. Appl. Energy 2017, 206, 911-933. [CrossRef]

11. Huang, T.C.; Zhang, Y.J. Reliability evaluation of microgrid considering incentive-based demand response. In Proceedings of the 2nd International Conference on Energy Materials and Applications (ICEMA), Hiroshima, Japan, 10-12 May 2017.

12. Song, Y.; Hill, D.J.; Liu, T.; Zheng, Y. A distributed framework for stability evaluation and enhancement of inverter-based microgrids. IEEE Trans. Smart Grid 2017, 8, 3020-3034. [CrossRef]

13. Luna, A.C.; Meng, L.X.; Diaz, N.L.; Graells, M.; Vasquez, J.C.; Guerrero, J.M. Online energy management systems for microgrids: experimental validation and assessment framework. IEEE Trans. Power Electron. 2017, 33, 2201-2215. [CrossRef] 
14. Williams, N.J.; Jaramillo, P.; Taneja, J. An investment risk assessment of microgrid utilities for rural electrification using the stochastic techno-economic microgrid model: A case study in Rwanda. Energy Sustain. Dev. 2018, 42, 87-96. [CrossRef]

15. Nosratabadi, S.M.; Hooshmand, R.A.; Gholipour, E.; Rahimi, S. Modeling and simulation of long term stochastic assessment in industrial microgrids proficiency considering renewable resources and load growth. Simul. Model. Pract. Theory 2017, 75, 77-95. [CrossRef]

16. Edinger, R.; Kaul, S. Humankind's detour toward sustainability: Past, present, and future of renewable energies and electric power generation. Renew. Sustain. Energy Rev. 2000, 4, 295-313. [CrossRef]

17. Farfan, J.; Breyer, C. Structural changes of global power generation capacity towards sustainability and the risk of stranded investments supported by a sustainability indicator. J. Clean. Prod. 2017, 141, 370-384. [CrossRef]

18. Katz, R.L.; Shirkhoda, A. Sustainability assessment of power generation in combination with lng evaporation: A comparison of lca methods and exergy analysis. Technol. Policy Manag. 2013, 55, 1995-2000.

19. Rodríguez-Serrano, I.; Caldés, N.; Rúa, C.D.L.; Lechón, Y. Assessing the three sustainability pillars through the Framework for Integrated Sustainability Assessment (FISA): Case study of a Solar Thermal Electricity project in Mexico. J. Clean. Prod. 2017, 2, 179. [CrossRef]

20. Inoussah, M.; Adolphe, M.; Daniel, L. Assessment of sustainability indicators of thermoelectric power generation in cameroon using exergetic analysis tools assessment of sustainability indicators of thermoelectric power generation in cameroon using exergetic analysis tools. Energy Power Eng. 2017, 9, 22-39. [CrossRef]

21. Wu, Y.N.; Chen, J.; Liu, L.R. Construction of China's smart grid information system analysis. Renew. Sustain. Energy Rev. 2011, 15, 4236-4241. [CrossRef]

22. Feron, S.; Heinrichs, H.; Cordero, R.R. Sustainability of rural electrification programs based on off-grid photovoltaic (PV) systems in Chile. Energy Sustain. Soc. 2016, 6, 32. [CrossRef]

23. Zhao, H.; Li, N. Performance evaluation for sustainability of strong smart grid by using stochastic AHP and fuzzy TOPSIS methods. Sustainability 2016, 8, 129. [CrossRef]

24. Hwang, C.; Yoon, K. Multiple Attribute Decision Making; Springer: Berlin/Heidelberg, Germany, 1981; pp. 132-158, ISBN 9783540105589.

25. Deng, J.L. Introduction to Grey system theory. J. Grey Syst. 1989, 1, 1-24.

26. Deng, J. The Grey Control System, 2nd ed.; Huazhong University of Science \& Technology Press: Wuhan, China, 1993; pp. 10-135, ISBN 9787560906799.

27. Liu, S.F. Grey Information: Theory and Practical Applications, 1st ed.; Springer: Berlin/Heidelberg, Germany, 2006; pp. 85-132, ISBN 1849969930.

28. Liu, S.F.; Xie, N.M.; Forrest, J. On new models of grey incidence analysis based on visual angle of similarity and nearness. Syst. Eng.-Theory Pract. 2010, 30, 881-887.

29. Cherkassky, V. The Nature of Statistical Learning Theory; Springer: Berlin/Heidelberg, Germany, 1995; pp. 988-999, ISBN 9780387987804.

30. Suykens, J.A.; Lukas, L.; Van Dooren, P.; De Moor, B.; Vandewalle, J. Least squares support vector machine classifiers: A large scale algorithm. In Proceedings of the European Conference on Circuit Theory and Design, Stresa, Italy, 29 August-2 September 1999; 1999.

31. Suykens, J.A.; Brabanter, J.D.; Lukas, L.; Vandewalle, J. Weighted least squares support vector machines: Robustness and sparse approximation. Neurocomputing 2002, 48, 85-105. [CrossRef]

32. Suykens, J.A.; Vandewalle, J. Least squares support vector machine classifiers. Neural Process. Lett. 1999, 9, 293-300. [CrossRef]

33. Smola, A.; Scholkopf, B. On a Kernel based method for pattern recognition, regression, approximation and operator inversion. Algorithmica 1998, 22, 211-231. [CrossRef]

34. Zhu, S.M.; Yang, M.; Han, X.S. Short-term generation forecast of wind farm using SVM-GARCH approach. In Proceedings of the IEEE International Conference on Power System Technology, Auckland, New Zealand, 30 October-2 November 2012.

35. Wang, J.; Song, Z.; Ran, R. Short-term photovoltaic power generation rolling forecast based on optimized SVM. Proc. CSU-EPSA 2016, 28, 9-13.

36. Malvoni, M.; Giorgi, M.G.D.; Congedo, P.M. Data on support vector machines (SVM) model to forecast photovoltaic power. Data Brief 2016, 9, 13-16. [CrossRef] [PubMed]

37. Xian, G. Data fitting experiments of LS-WSVM. Comput. Eng. Appl. 2008, 44, 36-38. 
38. Li, G.C.; You, J.C.; Liu, X.W. Support Vector Machine (SVM) based prestack AVO inversion and its applications. J. Appl. Geophys. 2015, 120, 60-68. [CrossRef]

39. Zughrat, A.; Mahfouf, M.; Thornton, S. Performance evaluation of SVM and iterative FSVM classifiers with bootstrapping-based over-sampling and under-sampling. In Proceedings of the IEEE International Conference on Fuzzy Systems, Istanbul, Turkey, 2-5 August 2015.

40. Jiang, X.; Lu, W.X.; Zhao, H.Q.; Yang, Q.C.; Chen, M. Quantitative evaluation of mining geo-environmental quality in Northeast China: Comprehensive index method and support vector machine models. Environ. Earth Sci. 2015, 73, 7945-7955. [CrossRef]

41. Chen, G.Y.; Xie, W.F. Pattern recognition with SVM and dual-tree complex wavelets. Image Vis. Comput. 2007, 25, 960-966. [CrossRef]

42. Wu, Y.C.; Lee, Y.S.; Yang, J.C. Robust and efficient multiclass SVM models for phrase pattern recognition. Pattern Recognit. 2008, 41, 2874-2889. [CrossRef]

43. Wang, A.; Yuan, W.; Liu, J.; Yu, Z.; Li, H. A novel pattern recognition algorithm: Combining ART network with SVM to reconstruct a multi-class classifier. Comput. Math. Appl. 2009, 57, 1908-1914. [CrossRef]

44. Pan, W.T. A new fruit fly optimization algorithm: Taking the financial distress model as an example. Knowl.-Based Syst. 2012, 26, 69-74. [CrossRef]

(C) 2018 by the authors. Licensee MDPI, Basel, Switzerland. This article is an open access article distributed under the terms and conditions of the Creative Commons Attribution (CC BY) license (http:/ / creativecommons.org/licenses/by/4.0/). 